\title{
Monitoring respiratory muscle strength assists in early diagnosis of respiratory dysfunction as opposed to the isolated use of pulmonary function evaluation in amyotrophic lateral sclerosis
}

Monitoramento da força muscular respiratória em detrimento do uso isolado da avaliação da função pulmonar para o diagnóstico precoce de disfunção respiratória em pacientes com esclerose lateral amiotrófica

Guilherme Fregonezi', Palomma Russelly Saldanha Araújo ${ }^{1}$, Tathiana Lindemberg Ferreira Macêdo ', Mario Emilio Dourado Junior², Vanessa Regiane Resqueti ${ }^{2}$ Armele de Fátima Dornelas de Andrade ${ }^{3}$

\begin{abstract}
Objective: It was study the relationship between respiratory muscle strength and forced vital capacity (FVC) in patients with amyotrophic lateral sclerosis (ALS) versus healthy subjects. Methods: Pulmonary function and respiratory muscle strength [maximal inspiratory (PImax), maximal expiratory (PEmax) and sniff nasal inspiratory pressure (SNIP)] were assessed in patients with ALS and healthy subjects, matched using cutoffs established in the literature for impaired pulmonary function and respiratory muscle weakness. Results: Twenty-eight ALS patients and 28 healthy subjects were studied. We found sensitivity and specificity for PImax, PEmax and SNIP of 75/58\%, 81/67\% and 75/67\%. The Receiver Operating Characteristic curve (ROC curve) indicated that the variables PImax, PEmax and SNIP can identify differences in respiratory muscle strength between ALS and healthy individuals at 0.89, 0.9 and 0.82 , respectively. A positive correlation was recorded between FVC (\%) versus SNIP, PImax and PEmax. Conclusion: In ALS, monitoring respiratory muscle strength assists in early diagnosis of respiratory dysfunction as opposed to the isolated use of FVC.
\end{abstract}

Key words: muscle weakness, neuromuscular diseases, pulmonary function test, respiratory muscles.

\section{RESUMO}

Objetivo: Estudar a relação entre a força dos músculos respiratórios e a capacidade vital forçada (CVF) em pacientes com esclerose lateral amiotrófica (ELA) e sujeitos saudáveis. Métodos: Avaliamos a função pulmonar e a força dos músculos respiratórios [pressão inspiratória (PImax), pressão expiratória (PEmax) e pressão inspiratória nasal de sniff (SNIP)] utilizando pontos de corte estabelecidos na literatura para diagnóstico de fraqueza muscular respiratória. Resultados: Foram estudados 28 pacientes com ELA e 28 sujeitos saudáveis. Encontramos sensibilidade e especificidade para PImax, PEmax e SNIP de 75/58\%, 81/67\% e 75/67\%. A curva ROC (Receiver Operating Characteristic) indicou que as variáveis PImax, PEmax e SNIP podem identificar diferenças na força dos músculos respiratórios em pacientes com ELA versus sujeitos saudáveis em 0,89, 0,9 e 0,82 respectivamente. Foi encontrada uma correlação positiva entre CVF (\%) e SNIP, PImax e PEmax. Conclusão: Em pacientes com ELA, o monitoramento da força muscular respiratória auxilia no diagnóstico precoce da disfunção em detrimento do uso da CVF isolada.

Palavras-Chave: debilidade muscular, doenças neuromusculares, teste de função pulmonar, músculos respiratórios.

\footnotetext{
1PneumoCardioVascular and Respiratory Muscle Performance, Department of Physical Therapy, Federal University of Rio Grande do Norte (UFRN), Natal RN, Brazil; ${ }^{2}$ Onofre Lopes University Hospital, UFRN, Natal RN, Brazil;

${ }^{3}$ Department of Physiotherapy, Laboratory of Cardiopulmonary Physiotherapy, Federal University of Pernambuco (UFPE), Pernambuco PE, Brazil. Correspondence: Guilherme Fregonezi; Departamento de Fisioterapia, Universidade Federal do Rio Grande do Norte, Campus Universitário Lagoa Nova Caixa Postal 1524; 59072-970 Natal RN - Brasil; E-mail: fregonezi@ufrnet.br

Support: This work was supported by the CNPq Brazil (number: 301661/2009-0) and Programa Nacional de Cooperação Acadêmica - Ação Novas Fronteiras (Procad-NF) number 764/2010-UFRN-UFMG-UFPE.

Conflict of interest: There is no conflict of interest to declare.

Received 04 May 2012; Received in final form 08 August 2012; Received in final form 15 August 2012.
} 
Amyotrophic lateral sclerosis (ALS) is a neurodegenerative disease that causes loss or death of the upper and lower motor neurons ${ }^{1}$. Symptoms typically appear in the $50^{\text {th }}$ decade of life, and the disease follows a specific clinical course. In general, survival does not exceed three years in $76 \%$ of cases and five to ten years in 8 to $16 \%$ of cases $^{2}$. Clinically, ALS is characterized by loss of function in the skeletal muscles; with regard to prognosis of the disease, recent data in the literature have identified the primary clinical cause of death as respiratory failure in $70 \%$ of cases ${ }^{3-5}$. Respiratory failure is characterized by hypoxemia and/or hypercapnia, or a combination of both, and is directly associated to weakness in respiratory muscles ${ }^{6-9}$.

Evaluation of forced vital capacity (FVC) through spirometry has been widely used as an important tool for the monitoring of pulmonary function in ALS patients. However, the assessment of respiratory muscle strength through maximal inspiratory and experitory pressures (PImax, PEmax) and sniff nasal inspiratory pressure (SNIP) has become increasingly relevant in the early diagnosis of respiratory muscle weakness, as demonstrated in other neurological disease ${ }^{10,11}$. Despite the complementarity of respiratory muscle strength tests, recent studies have shown that these tests and pulmonary function assessments are not commonly used to monitor the respiratory health of patients with ALS. A recent investigation ${ }^{12}$ demonstrated that only $38 \%$ of clinical neurologists conduct some type of respiratory evaluation in their first contact with patients, and these tests are almost never repeated at reassessment. Among clinicians who requested some form of written information, evaluation of respiratory muscle strength was rare. PImax/PEmax was requested by only $6 \%$ of physicians and SNIP in $17 \%$ of cases, either at each visit or only when symptoms were present. The present study aimed to analyze the relationship between forced vital capacity and measurements of respiratory muscle strength in patients with ALS and matched healthy subjects.

\section{METHOD}

\section{Subjects}

This is a cross-sectional study of patients diagnosed with ALS by a neurologist, treated at the Multidisciplinary Clinic for Neuromuscular Diseases, and healthy individuals recruited from the university community. Patients were included by sample of convenience and assessed from January 2009 to July 2011, and healthy subjects were recruited and evaluated over the same period, paired by gender, age, height and body weight. All patients monitored by the multidisciplinary team and healthy participants had no respiratory or cardiac diseases. Healthy individuals and those suffering from ALS were included in the study after being informed about its nature and purpose and giving written informed consent. The investigation was conducted in accordance with Resolution 196/96 of the National Health Council and approved by the Onofre Lopes Hospital Research Ethics Committee (Protocol n 239/08).

\section{Study design}

All selected participants were submitted to anthropometric evaluation, forced vital capacity and respiratory muscle strength testing. Examinations of patients and healthy subjects took place on one day and were performed by the same examiner.

\section{Anthropometric assessment}

Weight was determined on a WELMY electronic balance (WELMY, Santa Bárbara do Oeste, Paraná, Brazil). Both height and weight were assessed with individuals barefoot, standing upright and wearing lightweight clothing. This was followed by the calculation of Body Mass Index (BMI) using the formula: BMI: weight $(\mathrm{kg}) /$ height $^{2}(\mathrm{~m})$.

\section{Forced spirometry}

Technical procedures, acceptability and reproducibility criteria, interpretive values, standardization and equipment were in accordance with American Thoracic Society/ European Respiratory Society recommendations ${ }^{13}$, and all patients were valued in seated position. Forced expiratory volume in the first second $\left(\mathrm{FEV}_{1}\right), \mathrm{FVC}$ and the $\mathrm{FEV}_{1} / \mathrm{FVC}$ relationship in their absolute and relative values were considered, with the latter obtained by comparison with the normal curve for all spirometric variables in relation to the Brazilian population ${ }^{14}$. A DATOSPIR 70 (Siblemed, Barcelona, Spain) device was used, calibrated daily. With respect to cutoffs for impaired lung function according to FVC, we used FVC $<75 \%$ of the predicted value, as described in the literature ${ }^{15}$.

\section{Respiratory muscle strength and sniff nasal inspiratory pressure}

Respiratory muscle strength was assessed by maximal static PImax, PEmax and SNIP using an MVD300 digital manometer (GlobalMed, Porto Alegre, Brazil), and results obtained were analyzed in absolute and relative values. Prior to each test, participants were given detailed instructions and a demonstration of the procedure by the examiner. PImax was measured following maximal inspiration from residual volume and PEmax was obtained through maximal expiration from total lung capacity ${ }^{16}$. The highest value obtained from at least five tests was considered, with three acceptable maneuvers ${ }^{13,17}$. O SNIP was evaluated according to standardized methodology ${ }^{18,19}$. The test was performed with one nostril occluded by a nasal plug, while the other remained unobstructed. Effort performed at the end of a relaxed expiration was identified as the functional residual capacity. A cutoff point was used to diagnose respiratory muscle weakness ${ }^{20}$, based on the mean of the normal value minus 1.96 standard deviations, 
in accordance with reference values for maximal respiratory pressures and sniff nasal inspiratory pressure published in previous studies ${ }^{21,22}$. Respective values for male and female were: PImax: $56.1 \mathrm{cmH}_{2} \mathrm{O}$ and $53.4 \mathrm{cmH}_{2} \mathrm{O}$; PEmax: $70.6 \mathrm{cmH}_{2} \mathrm{O}$ and $57.2 \mathrm{cmH}_{2} \mathrm{O}$; and SNIP $61.1 \mathrm{cmH}_{2} \mathrm{O}$ and $57.2 \mathrm{cmH}_{2} \mathrm{O}$.

\section{Statistical analysis}

Results are expressed as mean and standard deviation. The unpaired $t$-test was applied to compare anthropometric, lung function and respiratory muscle strength values between ALS patients and healthy subjects. Pearson's correlation was used to verify the association between the variables pulmonary function and respiratory muscle strength, and simple linear regression was employed to analyze the relationship between PImax and PEmax in ALS patients and healthy subjects. A study of specificity and sensitivity was performed for each variable of respiratory muscle strength (PImax, PEmax and SNIP) in relation to FVC, in addition to an analysis of the Receiver Operating Characteristic curve (ROC curve) for respiratory muscle strength values of ALS patients in relation to those of healthy subjects. GraphPad Prism 4 software (GraphPad Software Inc., San Diego Califórnia USA) was used for all analyses, with a significance level of $p<0.05$ and bilateral approximation.

\section{RESULTS}

We evaluated 31 patients (19 men) with ALS and 28 healthy subjects (16 men). Three ALS patients were excluded for being unable to perform the maneuver required for respiratory muscle assessment. The final sample consisted of 28 individuals suffering from ALS (16 men) and 28 healthy subjects (16 men).

The average time since diagnosis was $44.8 \pm 5.9$ months. According to El Escorial criteria, 15 patients $(7$ males and 8 females) were diagnosed with definite ALS and 13 (9 men and 4 women) with probable ALS. With regard to type of classification, 5 individuals were classified as suffering from bulbar/first order motor neuron ALS and 23 (12 males and 11 females) with spinal/second order motor neuron ALS. Eight patients used orthosis (wheelchairs) for locomotion and 20 were able to walk unaided or with partial assistance provided by an orthosis brace. Regardless of the use of orthoses, all patients were capable of standing for weight and height analysis.

\section{Anthropometric characteristics}

Significant differences were recorded between the group of ALS sufferers and healthy volunteers with respect to weight $(p=0.029)$ and BMI $(p=0.004)$. Among females, significant differences were also found between weight $(p=0.029)$ and BMI $(p=0.001)$ for ALS patients in relation to healthy subjects. Anthropometric characteristics of the sample are described in Table 1.

\section{Spirometry and inspiratory and expiratory muscle strength}

In regard to pulmonary function, significant differences were observed for both male and female patients in relation to healthy participants for the variables FVC and $\mathrm{FEV}_{1}$, in absolute values and percentages of the predicted $\mathrm{FEV}_{1}$ / FVC ratio (Table 2). ALS patients were classified as suffering from mild restrictive ventilatory dysfunction. Regarding respiratory muscle strength, considering the cutoff points

Table 1. Anthropometric characteristics and pulmonary function in both groups.

\begin{tabular}{|c|c|c|}
\hline \multirow{2}{*}{ Subjects (n) } & ALS & Healthy subjects \\
\hline & 28 & 28 \\
\hline Gender (M/F) & $16 / 12$ & $16 / 12$ \\
\hline Age (years) & $54 \pm 12$ & $54.2 \pm 12.1$ \\
\hline Weight (kg) & $62.2 \pm 15.2$ & $70 \pm 10.3^{*}$ \\
\hline Height (m) & $1.63 \pm 0.1$ & $1.63 \pm 0.08$ \\
\hline BMI $\left(\mathrm{kg} / \mathrm{m}^{2}\right)$ & $23 \pm 4$ & $26 \pm 2.7^{\star}$ \\
\hline $\mathrm{FVC}(\mathrm{L})$ & $3.6 \pm 0.97$ & $2.3 \pm 1.3^{*}$ \\
\hline FVC $\left(\%_{\text {pred }}\right)$ & $93.6 \pm 8.7$ & $66.5 \pm 32 *$ \\
\hline $\mathrm{FEV}_{1}(\mathrm{~L})$ & $3 \pm 0.76$ & $1.9 \pm 1 *$ \\
\hline$F E V_{1}\left(\%_{\text {pred }}\right)$ & $97.6 \pm 8.7$ & $67.6 \pm 32^{\star}$ \\
\hline $\mathrm{FEV}_{1} / \mathrm{FVC}$ & $105 \pm 9$ & $83.6 \pm 13^{\star}$ \\
\hline FVC $(L)$ & $3.6 \pm 0.97$ & $2.3 \pm 1.3^{*}$ \\
\hline PImax $\left(\mathrm{cmH}_{2} \mathrm{O}\right)$ & $96.8 \pm 22.1$ & $51.2 \pm 31 * *$ \\
\hline $\operatorname{PEmax}\left(\mathrm{cmH}_{2} \mathrm{O}\right)$ & $126.1 \pm 32$ & $60.7 \pm 37 * \star$ \\
\hline $\operatorname{SNIP}\left(\mathrm{cmH}_{2} \mathrm{O}\right)$ & $108.4 \pm 22$ & $66.5 \pm 36 * \star$ \\
\hline SNIP/PImax & $1.13 \pm 0.15$ & $1.5 \pm 0.8 * *$ \\
\hline
\end{tabular}

Data are expressed as mean \pm standard deviation. * non-paired $t$-test $p \leq 0.05$ and ${ }^{* *}$ non-paired $t$-test $p \leq 0.01$. M: male; F: female; BMI: body mass index; FVC: forced vital capacity; FEV : forced expiratory volume in the first second; $\mathrm{FEV}_{1} / \mathrm{FVC}$ : ratio between forced expiratory volume in the first second and forced vital capacity; SNIP: sniff nasal inspiratory pressure; PImax: maximal inspiratory pressure; PEmax: maximal expiratory pressure; ALS: amyotrophic lateral sclerosis.

Table 2. Cross-Tab between forced vital capacity and cutoff points limits for diagnosis of respiratory muscle weakness.

\begin{tabular}{lcccccc} 
& \multicolumn{2}{c}{ PImax } & \multicolumn{2}{c}{ PEmax } & SNIP \\
\hline & Limits & Normal & Limits & Normal & Limits & Normal \\
\hline $\begin{array}{l}\text { FVC } \leq 75 \%_{\text {pred }} \\
16 \text { patients }\end{array}$ & $12(75 \%)$ & $4(25 \%)$ & $13(81.25 \%)$ & $3(18.75 \%)$ & $12(75 \%)$ & $4(25 \%)$ \\
$\begin{array}{l}\text { FVC }>75 \%_{\text {pred }} \\
12 \text { patients }\end{array}$ & $5(41.6 \%)$ & $7(58.3 \%)$ & $4(38.3 \%)$ & $8(66.6 \%)$ & $4(38.3 \%)$ & $8(66.6 \%)$ \\
\hline
\end{tabular}

FVC: forced vital capacity; SNIP: sniff nasal inspiratory pressure; PImax: maximal inspiratory pressure; PEmax: maximal expiratory pressure. Cutoff points limits: PImax $\hat{\delta}=56.1 \mathrm{cmH}_{2} \mathrm{O}$ e $+=53.4 \mathrm{cmH}_{2} \mathrm{O} ; \mathrm{PEmax} \hat{\delta}=70.6 \mathrm{cmH}_{2} \mathrm{O}$ and $q=57.2 \mathrm{cmH}_{2} \mathrm{O} ; \mathrm{SNIP} \hat{\jmath}=61.1 \mathrm{cmH}_{2} \mathrm{O}$ and $q=57.2 \mathrm{cmH}_{2} \mathrm{O}$. 
applied, all healthy volunteers exhibited respiratory muscle strength within the normal range. In the ALS group, 9 men (32\%) and 8 women (28\%) were classified with inspiratory muscle weakness, considering only PImax. When applying cutoff points for inspiratory muscle weakness tested by SNIP, we detected 9 men (32\%) and 7 women, while expiratory muscle weakness categorized by PEmax analysis identified 9 male (32\%) and 8 female patients (28\%). Results are shown in Fig 1.

After subdividing patients, just for descriptive analysis, into bulbar (5 subjects) and spinal ALS (23 individuals), FVC was found to be reduced in both groups (68.7 \pm 32.2 versus $66.2 \pm 32.3 \%$ pred, respectively). However, PImax, PEmax and SNIP values indicative of muscular weakness were lower in the bulbar ALS group when compared with the spinal ALS group (PImax: $45.6 \pm 35.7 \mathrm{cmH}_{2} \mathrm{O}$ versus $52.5 \pm 30 \mathrm{cmH}_{2} \mathrm{O}$; SNIP: $60.8 \pm 38.9 \mathrm{cmH}_{2} \mathrm{O}$ versus $67.7 \pm 37.6 \mathrm{cmH}_{2} \mathrm{O}$; PEmax: $49.6 \pm 21.7 \mathrm{cmH}_{2} \mathrm{O}$ vs $63.1 \pm 40 \mathrm{cmH}_{2} \mathrm{O}$ ) respectively.

Analysis of cutoff points suggested to diagnose inspiratory and expiratory muscle weakness versus reduced FVC $<75 \%_{\text {pred }}$ identified sensitivity and specificity for PImax, PEmax and SNIP of $75 \% / 58 \%, 81 \% / 67 \%$ and $75 \% / 67 \%$, respectively (Table 2). The ROC curve demonstrated high accuracy for PImax, PEmax and SNIP tests in detecting weakness in the respiratory muscles of ALS patients. The likelihood of randomly chosen patients obtaining PEmax, PImax and SNIP results lower than those recorded for a randomly selected healthy individuals is 0.90 (90\%), 0.89 (89\%) and 0.82 (82\%) respectively (Fig 2).

\section{Relationship between respiratory muscle strength and pulmonary function}

Considering the relationship between the strength of different respiratory muscles, Fig 1 shows an alteration in strength equilibrium between inspiratory and expiratory muscles in ALS patients. In healthy subjects, a relationship was observed in which PEmax $=16.46+1.13 *$ PImax, whereas in ALS patients PEmax $=28.9+0.73 *$ PImax.

PImax was positively correlated to SNIP in healthy individuals and ALS patients, with $\mathrm{r}=0.802$ and $\mathrm{r}=0.872$, respectively, and $\mathrm{p}<0.001$ for both groups. A positive correlation was recorded between FVC (\%)/SNIP, FVC \%/PImax and FVC (\%)/PEmax only among ALS patients, with $\mathrm{r}=0.748, \mathrm{r}=0.724$ and $\mathrm{r}=0.826$, respectively, and $\mathrm{p}<0.001$ (Fig 3).

\section{DISCUSSION}

The present study aimed to investigate the relationship between measurements of respiratory muscle strength and FVC in patients with amyotrophic lateral sclerosis versus healthy subjects. Furthermore, we sought to establish the importance of the correlation between respiratory muscle strength and spirometric variables, particularly forced vital capacity, in identifying early-onset respiratory muscle weakness in ALS patients. Despite the slight change in pulmonary function, the strength of respiratory muscles was already moderately to severely impaired.

In light of the need for early diagnosis of reduced lung function in patients with neuromuscular diseases, several measures to achieve this purpose have been described in the literature. Determining FVC by spirometry has been reported and applied as a simple and efficient mean ${ }^{23}$ of monitoring declining lung function. However, it is not sensitive to detecting early respiratory damage since respiratory symptoms are often not yet evident, despite the presence of alterations in respiratory muscle strength. Patients assessed in the present study exhibited restrictive ventilatory pattern, with $57 \%$ of patients showing diminished FVC, 75\% displaying reduced SNIP and 81\% demonstrating a decrease in PEmax. Likewise, according to the cutoff points applied in this investigation to diagnose respiratory muscle weakness, approximately $40 \%$ of patients exhibited loss of inspiratory and/or expiratory muscle strength, even when pulmonary function was preserved. Results found in the present study reinforce this fact. In a previous study, Tsara et al..$^{24}$ evaluated lung function through FVC in 28 individuals suffering from ALS and observed that $78.5 \%$ of patients showed reduced FVC and $89.5 \%$ of these demonstrated a decline in maximal respiratory pressure. Analysis of maximal respiratory pressures depicts the respiratory muscles as a whole, which is complemented by sniff nasal inspiratory pressure as an excellent assessment of muscular contraction in the diaphragm.

Correlations between other measurements have previously been described as aids to better understanding the progression of respiratory function and level of respiratory muscle weakness in these patients. Recently, Singh et al. ${ }^{25}$ conducted a prospective study with 26 ALS patients, evaluating FVC and motor amplitude of the phrenic nerve (PN-AMPs) as a potential technique for assessing respiratory function. The authors demonstrated that reduced phrenic nerve motor amplitude may be indicative of low FVC, facilitating measurement in patients unable to perform the spirometry maneuver since it relies on individual effort. Even when applying another means of determining the electrical activity of respiratory muscles, the authors emphasized the importance of using measures complementary to FVC to assess declining function in ALS patients. Stimulation of the phrenic nerve has the advantage of detecting dysfunction with low PN-AMP. Previously, few studies aimed at investigating the relationship between the strength of respiratory muscles. Silva et al. ${ }^{26}$ analyzed 20 ALS sufferers (13 diagnosed with spinal ALS and 7 with bulbar ALS) with a view to correlating indicators used in nutritional, 
Healhty subjects
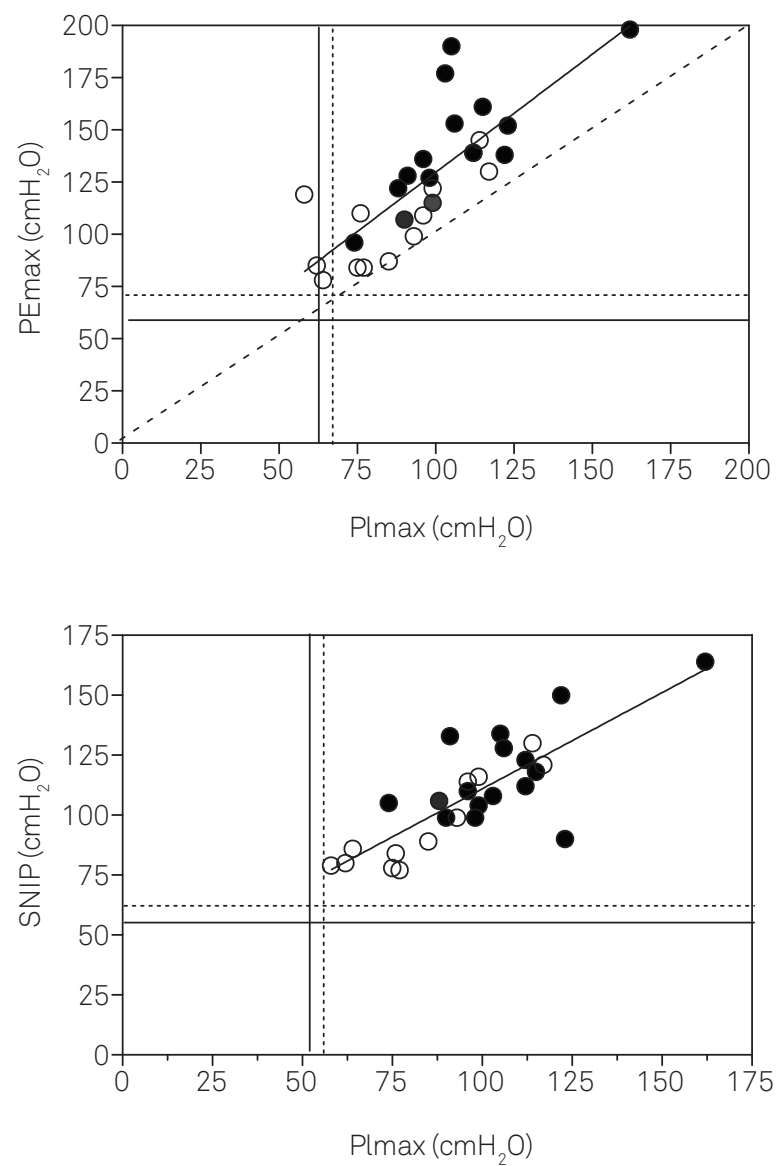

ALS
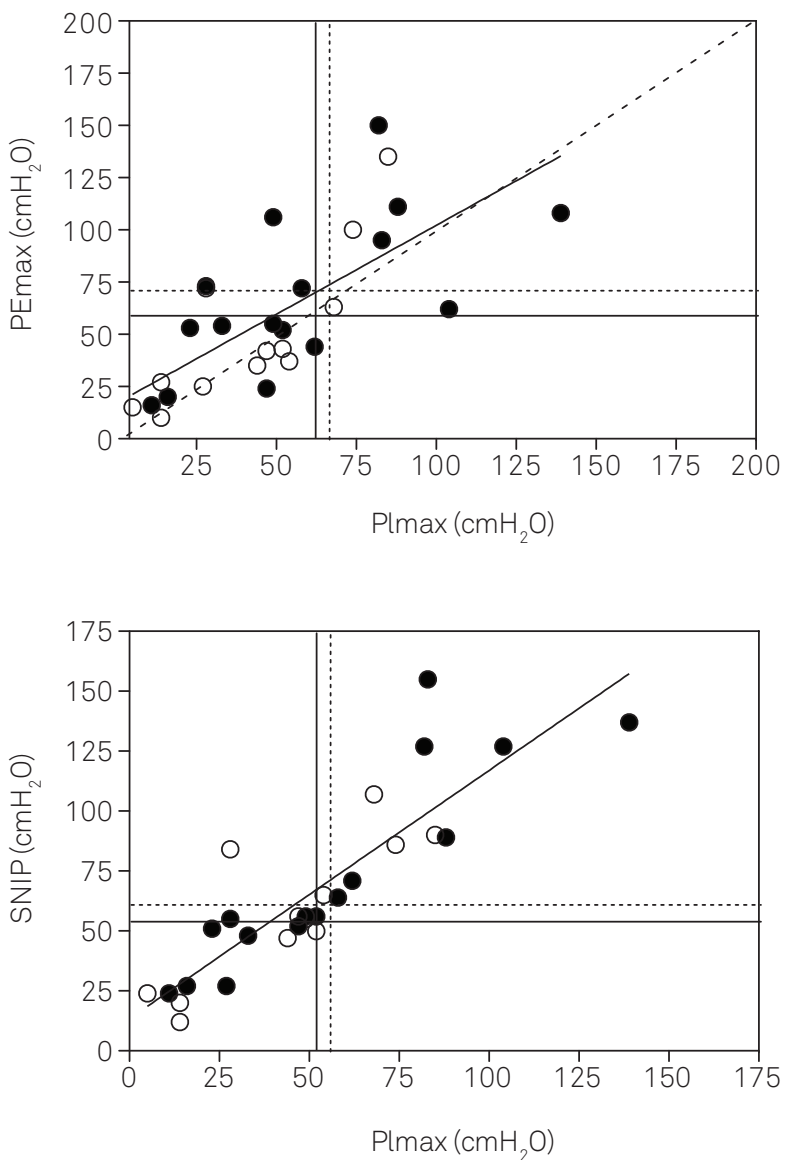

Male: close circle; Female: open circle. Cut of points for female are represented with continues line and for male dotted line.

Fig 1. Relationship between inspiratory maximal pressure (PImax) versus expiratory maximal pressure (PEmax) and sniff nasal inspiratory pressure (SNIP) in healthy subjects and amyotrophic lateral sclerosis patients.

functional and respiratory assessment. In patients with spinal ALS, the authors found correlations between PImax and PEmax of $r=-0.76$; PEmax and pulse oximetry of $\mathrm{r}=0.58$; ALSFRS-R score and percentage weight loss $(\% \mathrm{WL}) \mathrm{r}=0.59$ and between PImax and ALSFRS-R score $r=0.65$. In the bulbar group, a correlation was observed between PEmax and BMI ( $\mathrm{r}=0.97)$. Moreover, the bulbar group also exhibited severely compromised respiratory muscles and pulmonary function, with mean PImax of $24.1 \mathrm{cmH}_{2} \mathrm{O}$ and PEmax of $35 \mathrm{cmH}_{2} \mathrm{O}$ and $\mathrm{FVC}$ of $54 \%$ pred In the spinal group, respiratory muscle strength and lung function showed a moderate decrease, with PImax of $61.1 \mathrm{cmH}_{2} \mathrm{O}$, PEmax at $62.3 \mathrm{cmH}_{2} \mathrm{O}$ and FVC of $84 \%_{\text {pred }}$. As in our study, this investigation demonstrates that, although loss of strength was already present in respiratory muscles, pulmonary function in the spinal ALS group showed a slower decline, in contrast with the bulbar ALS group, which was evident even in a smaller sample of patients.

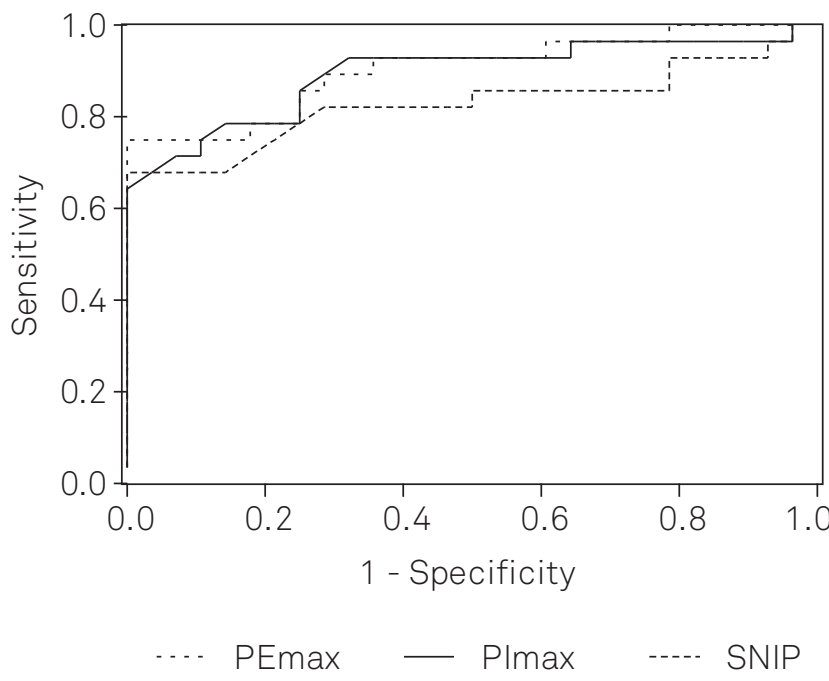

PImax: inspiratory maximal pressure; PEmax: expiratory maximal pressure; SNIP: sniff nasal inspiratory pressure.

Fig 2. Receiver Operating Characteristic curve (ROC curve) for respiratory muscle strength values of amyotrophic lateral sclerosis patients in relation to those of healthy subjects. 


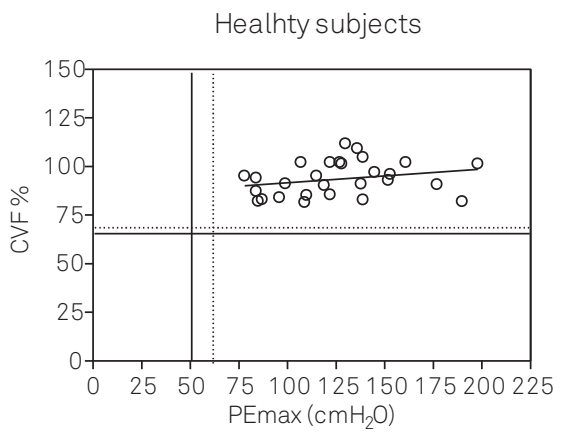

ALS

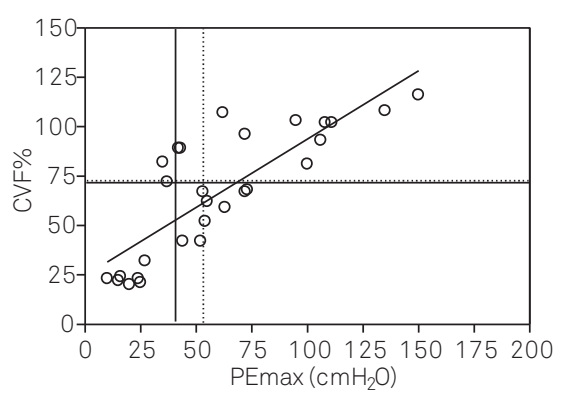

Healthy Subjects

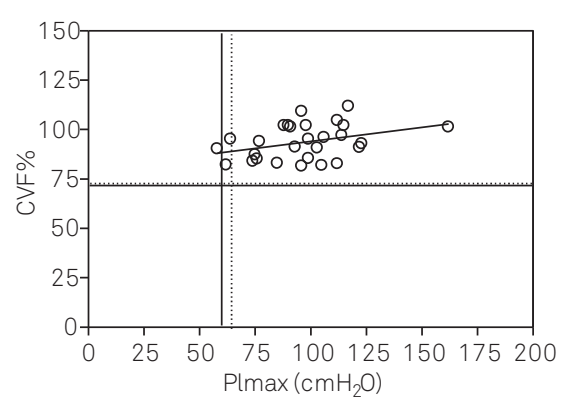

ALS

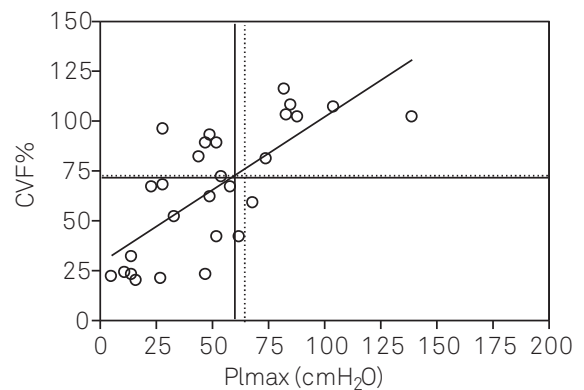

Healthy Subjects

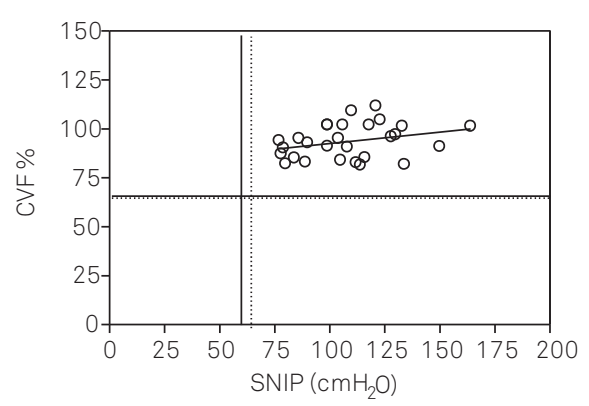

ALS

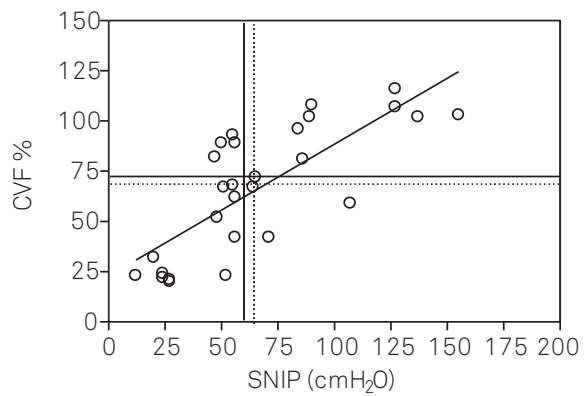

Fig 3. Relationship between forced vital capacity percentage (FVC\%) of the predicted value and maximal expiratory pressure (PEmax), maximal inspiratory pressure (PImax) and sniff nasal inspiratory pressure (SNIP) in amyotrophic lateral sclerosis patients and healthy subjects.

In a similar study, Almeida et al. ${ }^{27}$ evaluated 16 patients diagnosed with probable or definite ALS over 8 months, using spirometry, maximal respiratory pressures, arterial gasometry, pulse oximetry, BMI and percentage weight loss. The authors found that $\mathrm{PCO}_{2}$ was a significant parameter to monitor the evolution of the disease during the study period ( $\mathrm{p}=0.051)$. Significant correlations were also observed between PImax and PEmax ( $\mathrm{r}=0.83$ ); BMI and PImax (r=0.70); BMI and PEmax ( $\mathrm{r}=0.72)$; pulse oximetry and forced vital capacity $(\mathrm{r}=0.57)$. At the same time, this study shows moderate alterations in respiratory muscle strength with PImax of $65.6 \mathrm{cmH}_{2} \mathrm{O}$ and PEmax at $74.2 \mathrm{cmH}_{2} \mathrm{O}$, with few changes in FVC\% $\left(82 \%_{\text {pred }}\right)$. Although both studies identify important information with respect to respiratory elements, they present little new evidence regarding respiratory muscle strength and spirometry. By contrast, the present study assesses the relationship between respiratory muscle strength and spirometry, establishing parameters that can be used as a reference and determining cutoff points for respiratory muscle strength, clearly demonstrating the difference between men and women in the functional loss of strength in these muscles.

Several other studies have been published with the purpose of establishing a relationship between the degree of respiratory muscle weakness and distribution of weakness (diaphragmatic versus overall muscle weakness) and lung volumes. Qureshi et al. ${ }^{28}$ investigated risk factors and predictors of disease progression in 106 healthy subjects over 12 months. They observed normal total lung capacity (TLC), elevated residual volume, reduced vital capacity and diminished respiratory muscle strength (inspiratory and expiratory), with a greater decline in PEmax than maximal PImax. The study showed that a marked reduction in PEmax determines increased residual volume (RV), which clinically translates into lower expiratory efficiency. Other authors have confirmed the relationship between muscular alteration already present and pulmonary function. In 213 patients, Fallat et al..$^{29}$ reported preserved FVC and TLC associated with an accentuated change in $\mathrm{RV}$ and maximal voluntary ventilation. The same authors established a relationship between symptoms and lung function, observing that, despite existing muscular alteration, respiratory symptoms were only reported by patients after a significant decrease in pulmonary function ${ }^{28}$.

A potential limitation of our study is the small sample size due to the limited time and few resources available during the study period well defined. Furthermore, the heterogeneity of sample size that represents the ALS cases in health care in our outpatients clinics. However the possible weak point of the study, the results add new perspective in terms of respiratory assessment in ALS patients.

The present study demonstrated that in patients with ALS changes in balance and the monitoring of respiratory muscle strength contribute towards understanding the decline in respiratory muscles and pulmonary function identified prior to respiratory muscle weakness, as opposed to using only forced vital capacity to assess the progression of respiratory function. 
1. Lima NMFV, Nucci A. Clinical attention and assistance profile of patients with amyotrophic lateral sclerosis. Arq Neuropsiquiatr 2011;69:170-175.

2. Hirtz D, Thurman DJ, Gwinn-Hardy K, Mohamed M, Chaudhuri AR, Zalutsky R. How common are the common neurological disorders? Neurology 2007:68;326-337.

3. Spataro R, LoRe M, Piccoli T, Piccoli F, La Bella V. Causes and place of death in Italian patients with amyotrophic lateral sclerosis. Acta Neurol Scand 2010;122:217-223.

4. Kurian KM, Forbes RB, Colville S, Swingler RJ. Cause of death and clinical grading criteria in a cohort of amyotrophic lateral sclerosis cases undergoing autopsy from the Scottish Motor Neurone Disease Register.J Neurol Neurosurg Psychiatry 2009;80:84-87.

5. Corcia P, Pradat PF, Salachas F, et al. Causes of death in a post-mortem series of ALS patients. Amyotroph Lateral Scler 2008;9:59-62.

6. Resqueti VR, Araújo PRS, Dourado Junior ME, Fregonezi GAF. Esclerose lateral amiotrófica (ELA) e músculos respiratórios. Ter Man 2011;9:503-508.

7. Uldry C, Janssens JP, de Muralt B, Fitting JW. Sniff nasal inspiratory pressure in patients with chronic obstructive pulmonary disease. Eur Respir J 1997;10:1292-1296.

8. Nava S, Ambrosino N, Crotti P, Fracchia C, Rampulla C. Recruitment of some respiratory muscles during three maximal inspiratory maneuvers. Thorax 1993;48:702-707.

9. Katagiri M, Abe T, Yokoba M, Dobashi Y, Tomita T, Easton PA. Neck and abdominal muscle activity during a sniff. Respir Med 2003;97:1027-1035.

10. Hart N, Polkey MI, Sharshar T, et al. Limitations of sniff nasal pressure in patients with severe neuromuscular weakness Neurol Neurosurg Psychiatry 2003;74:1685-1687.

11. Azevedo IG, Severino FG, Araújo TL, Resqueti VR, Bruno S, Fregonezi GAF. Relação entre pressão inspiratória nasal e pressão inspiratória máxima em pacientes com distrofia miotônica. Ter Man 2010;8:224-230.

12. O'Neill CL, Williams TL, Peel ET, et al. Non-invasive ventilation in motor neuron disease: an update of current UK practice. J Neurol Neurosurg Psychiatry 2012;83:371-376.

13. Miller MR, Hankinson J, Brusasco V, et al. ATS/ERS Task Force. Standardisation of spirometry. Eur Respir 2005;26:319-338.

14. Pereira CAC, Sato T, Rodrigues SC. New reference values for forced spirometry in white adults in Brazil.J Bras Pneumol 2007;33:397-406.

15. Lechtzin N, Wiener CM, Shade DM, Clawson L, Diette GB. Spirometry in the supine position improves the detection of diaphragmatic weakness in* patients with amyotrophic lateral sclerosis. Chest 2002;121;436-442.
16. Black LF, Hyatt RE. Maximal respiratory pressures: normal values and relationship to age and sex. Am Rev Respir Dis 1969;99:696-702.

17. Neder JA, Andreoni S, Lerario MC, Nery LE. References values for lung function tests. Maximal respiratory pressures and voluntary ventilation. Braz J Med Biol Res 1999;32:719-727.

18. Severino FG, Resqueti VR, Bruno SS, Azevedo IG, Vieira RHG, Fregonezi GAF. Comparação entre o manovacuômetro nacional e o importado para medida da pressão inspiratória nasal. Rev Bras Fisioter 2010;14:426-431.

19. Lofaso F, Nicot F, Lejaille M, et al. Sniff nasal inspiratory pressure: what is the optimal number of sniffs? Eur Respir J 2006;27:980-982.

20. Steier J, Kaul S, Seymour J, et al. The value of multiple tests of respiratory muscle strength. Thorax 2007;62:975-980.

21. Araujo PRS, Resqueti VR, Nascimento Jr JF, et al. Maximal sniff nasal inspiratory pressure in Brazilian healthy subjects: a multicenter study. Maximal respiratory pressure in Brazilian health population: a multicenter study (in press).

22. Fregonezi GAF, Araujo PRS, Dornelas de Andrade AF, et al. Maximal sniff nasal inspiratory pressure in Brazilian healthy subjects: a multicenter study. In: XXI European Annual Congress, 2011, Amsterdam. Eur Resp J 2011;239.

23. Lechtzin N, Wiener CM, Shade DM, et al. Spirometry in the supine position improves the detection of diaphragmatic weakness in patients with amyotrophic lateral sclerosis. Chest 2002;121:436-442.

24. Tsara V, Serasli E, Steiropoulos P, Tsorova A, Antoniadou M, Zisi P. Respiratory function in amyotrophic lateral sclerosis patients. The role of sleep studies. Hippokrattia 2010;14:33-36.

25. Singh D, Verma R, Garg RK, et al. Assessment of respiratory functions by spirometry and phrenic nerve studies in patients of amyotrophic lateral sclerosis. J Neurol Sci 2011;306:76-81.

26. Silva LBC, Mourão LF, Silva AA, et al. Amyotrophic lateral sclerosis: combined nutritional, respiratory and functional assessment. Arq Neuropsiquiatr 2008:66:354-359.

27. Almeida SRM, Silva LBC, Guerreiro CAM, Nucci A. Amyotrophic lateral sclerosis: prospective study on respiratory parameters. Arq Neuropsiquiatr 2010;68:258-262

28. Qureshi MM, Hayden D, Urbinelli L, et al. Analysis of factors that modify susceptibility and rate of progression in amyotrophic lateral sclerosis (ALS). Amyotrophic Lateral Sclerosis 2006;7:173-182.

29. Fallat RJ, Jewitt B, Bass M, Kamm B, Norris FH Jr. Spirometry in amyotrophic lateral sclerosis. Arch Neurol 1979;36:74-80. 